\title{
The Effect of Case Management for Schizophrenia Clients in China
}

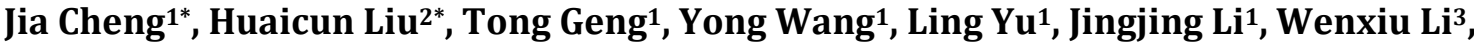 \\ Caili Chen', Guizhong Yao1"
}

${ }^{1}$ Peking University Sixth Hospital and Peking University Institute of Mental Health and Key Laboratory of Mental Health, NHC (Peking University) and National Clinical Research Center for Mental Disorders (Peking University Sixth Hospital), Beijing, China

${ }^{2}$ Peking University Health Science Center, Beijing, China

${ }^{3}$ Mental Health Prevention Hospital of Haidian District, Beijing, China

Email: "guizhongyao63@163.com

How to cite this paper: Cheng, J., Liu, H.C., Geng, T., Wang, Y., Yu, L., Li, J.J., Li, W.X., Chen, C.L. and Yao, G.Z. (2020) The Effect of Case Management for Schizophrenia Clients in China. Journal of Behavioral and Brain Science, 10, 297-310. https://doi.org/10.4236/jbbs.2020.108019

Received: June 29, 2020

Accepted: July 24, 2020

Published: July 27, 2020

Copyright (c) 2020 by author(s) and Scientific Research Publishing Inc. This work is licensed under the Creative Commons Attribution International License (CC BY 4.0).

http://creativecommons.org/licenses/by/4.0/

\begin{abstract}
Background: The aim at this study is to establish the effectiveness of case management (CM) compared to care as usual (CAU) in patients with schizophrenia. Methods: 128 patients with schizophrenia were recruited from the community of Haidian District (Beijing, China), 68 patients in the CM group and 60 patients in the CAU group. Efficacy and safety information were assessed at one year follow-up. The relapse rate was similar in both groups after 12 months followed up (7\% and 5\%). The withdraw rate was significant lower in CM group compared with CAU group (10\% and 36\%). Results: There is no significant difference in PANSS, PSP and SSMI score between 2 groups at each visit. Between endpoint and baseline, there is a significant improvement on PANSS negative score and PSP in patients treated with CM, while CAU group was not significantly changed. Conclusions: There is a possible effectiveness of CM group of improving negative symptoms and social function in schizophrenia clients.
\end{abstract}

\section{Keywords}

Case Management, Care as Usual, Schizophrenia Clients, PANSS Score

\section{Introduction}

People with severe mental illness have various needs for treatment, assistance, and support to have the best recovery opportunity. These needs include not only mental health services, but also general health services, education, employment, *These authors contributed equally to this work. 
housing, family services, etc. [1]. In the past few decades, significant changes have taken place in psychiatric treatment, especially to people with severe mental disorders throughout the Western World. The deinstitutionalization movement towards the 1960s and 1970s changed the locus of treatment for most people with severe mental illnesses from the hospital to the community. For many mentally ill persons that are accustomed to be served as the hospital, it is complex and difficult to actively seek out psychiatric services from the community. Community services were losing contact with patients and failing to meet their complex psychiatric and social needs [2].

Case management arising as a response to this problem, is a means of coordinating the care of severely mentally disorder people in the community. It aims to enhance the continuity of care and its accessibility and efficiency.

There are a variety of different models of case management, including the brokerage, clinical, strengths, rehabilitation, and ACT models [3] [4] [5]. Strengths Case Management focuses on working with the client's skills rather than deficits. This model was developed for persons with severe mental disease tend to overemphasize the limits and impairments associated with psychiatric illnesses rather than concern the personal advantage that patients can use toward achieving individual goals. A great quantity of studies has been published about the efficacy and effectiveness of case management services, and also a lot of reviews covering these studies [4]-[10]. The results of these studies and reviews are divergent, but overall more intensive models like the Assertive Community Treatment model (ACT) seem to be more effective in ameliorating many outcomes relevant to people with severe mental illness. ACT tends to more effective against decreasing hospitalisation and maintains stability in the community. There is no significant difference between standard management in improving symptoms, quality of life, social and occupational functions [4] [9]. Standard case management is more effective than standard care on numbers maintaining contact with services, while approximately doubles the rate of hospital admissions. In addition, compared with standard care, case management did not improve mental health, social function or quality of life [11]. In this review it was also noted that there is some evidence that the strengths model of case management is more effective than other standard case management models of high or low intensity.

In Asia, various community programs have been adopted and studied in several countries to promote de-institutionalization, community psychiatric services and reduce relapses or readmission rates.

In China, the government has to implement the community severe mental illness management program (686 projects) from 2004. Thus, case management for clients with severe mental illness in the community is still in its infancy. Given the current state of development of resources for people with severe mental illness in the community and the limited resources overall, it is difficult to develop the assertive community service in China.

The pilot study presented here was conducted to evaluate the effects of the 
strengths model case management service on Chinese patients with schizophrenia recruited from five community health centers.

The main aim of the present study was to assess the effectiveness of a $\mathrm{CM}$ group and CAU group in patients with schizophrenia, to establish an evaluation system for clinical case management techniques for schizophrenia with Chinese characteristics.

\section{Methods}

This study has been conducted an one-year, longitudinal, experimental study which aims to compare the effectiveness of the case management and the care as usual. The subject, grouping, intervention, supervision and training, evaluation procedures and data analysis are described below.

\section{Subject}

Schizophrenia patients documented in the community mental health management system of Haidian District (Beijing, China), and met the following criteria was recruited between October 2010 to October 2012. Patients were randomly divided into two groups (CM group and CAU group) according to a 1:1 ratio with the block randomization.

Inclusion criteria:

Subjects enrolled in this study were required to meet the following criteria:

1) The subject had received the diagnosis of schizophrenia according to the International Classification of Diseases-10 (ICD-10) by two psychiatrists;

2) Not in acute phase (medication was stable in the last month, no hospital admission within the previous one year);

3) The subject was aged 18 - 60 years and the education level was above nine years;

4) Informed consent from the patients or their legal guardians.

Exclusion criteria:

Subjects were excluded if they had the idea or behavior of self-harm, suicide, assault or violence that cause harm to others or property damage.

\section{Grouping}

Subjects are volunteered as the one years of case management or standard community service, which is more to align with clinical reality. However, some of the subjects were lost during the follow-up because the patients could not be contacted.

\section{Intervention}

CAU group:

Patients received care as usual, no special intervention are added by the trail except regular assessment according to the protocol.

CM group:

A staff in the community health center provided a supportive service to assist clients to live independently in the community. A multidisciplinary team in the psychiatric hospital supervised their service. The staff in the community received 
case management training before starting the study and took turns in attending regular booster training after the study began. The case management model which we applied was the strengths model [12]. The service for the clients:

1) The community mental health staffs were assuming the role of case managers. The case load was 1:15.

2) The case manager conducted a comprehensive evaluation of the clinical and psychosocial needs of their clients, informed by the following eight fields: mental health, physical health, cope with stress, social interactions, work and educational leisure, daily activity and living skills, financial management, family support. The case manager was evaluated the present situation with their clients, together with their future goals and past experiences. After discussions and consultations, individual service plans for their clients are formulated. For the first month, clients had an interview for their case manager once a fortnight. Then they met monthly to review their plan. The case managers made detailed clinical notes of each meeting with their clients.

3) Consistent with a strengths-based approach, the intervention focused on the strengths, abilities, resources, and potential of people and their community.

4) The psychiatrist in the multidisciplinary team visited the community once a week to do the clinical work, including reviewing clients' mental states and medication regimes and making necessary adjustments.

5) The service to clients was provided for workdays, $9 \mathrm{am}-5 \mathrm{pm}$, face-to-face or by telephone.

6) Psychosocial education was delivered to clients and their family caregivers in a group education session once a week. These covered introductory knowledge of mental illness, medication information, how to communicate with clients, supporting the clients at home, how to prevent the relapse.

7) Emergency intervention: The community staff assessed clients that were thought to be in crisis and reported to the multidisciplinary team, who offered advice, earlier review of the client or inpatient admission, as appropriate.

8) Each case manager reminded their clients to see the doctor and supported their visit.

\section{Supervision and training}

1) Case managers in the community health center were experienced nurses, doctors, social workers.

2) Each case manager has a supervisor from the multidisciplinary team. They were supervised through review of their written records of their case management practice.

3) Multidisciplinary review meetings were held every week to discuss the recovery plans of the clients.

\section{Evaluation}

For all patients, the one year assessment period was dates from baseline with follow-up interviews scheduled for one month, three months, six months and twelve month by research assessors, who were senior psychiatrists. Following scales is used to do quantitative evaluation. 
1) The relapse criteria were consisting of four categories: Hospitalization due to deterioration of mental symptoms; The PANSS score increased by $25 \%$, or PANSS score increased by 10 points when baseline PANSS score was 40 points; CGI-S score of 6 or 7; The Significant self-injury behavior, clinically significant suicide and murder concept, violent behavior leading to injury or property damage.

2) The Chinese version of the PANSS has been validated, which consists of 30 items and offers three categories: positive, negative and general syndromes [13]. Psychotic symptoms occurring during one week prior to the interview are rated from 1 to 7 . The higher the PANSS score is, the more severe the psychotic symptoms the patient has.

3) The PSP scale was administered by trained raters. It scored in four domains: psychosocial functioning within four domains: socially useful activities, personal and social relationships, self-care, and disturbing and aggressive behavior. A higher domain score represents worse functional performance in each domain. The final global score is defined according to a summary instruction table converting four domain scores into a single, overall rating from 1 to 100 , where a higher score represents better personal and social function [14].

4) The Social Function 36 Scale (SF36) was used to evaluate the quality of patients' life, and the higher grades meaning the higher quality of life [15].

5) The Stigma Self-assessment Scale was used to evaluate patients' experiences of stigma and discrimination [16].

6) A Rating Scale for Extrapyramidal Side Effects (RSESE) was used to assess the drug's extrapyramidal side effects [17].

\section{Statistics}

We estimated the study group relapse rate is 30\%, the control group is $60 \%$. When $\alpha$ is $0.05, \beta$ is $0.1, n=(U \alpha+U \beta) 22 P(1-P) /(P 1-P 0) 2,47$ cases for each group, consider $20 \%$ drop rate, a total of 112 cases were needed. Statistical analyses were performed using SPSS software (version 17.0), with the significance level set at $\mathrm{p}=0.05$. Use Last Observation Carried Forward (LOCF) imputation method to fill in missing data. Chi square analysis for categorical variables and independent samples and Student's t test for continuous variables were used. Descriptive statistics were computed using means and standard deviations from continuous variables, and absolute frequencies and percentages for categorical variables.

Ethics

This study was approved by the Ethics Committee of the Peking University Sixth Hospital (2011-8-26-1) and was conducted in accordance with the ethical standards of the 1964 Declaration of Helsinki.

\section{Results}

In this study, we recruit the patients from the community mental health management system of Haidian District between the October 2010 and October 2012. A total of 128 people participated in this study, 60 people in the CAU 
group, and 68 people in CM group. And patients are volunteered for the one years of case management or standard community service. At the end of this study, there are only 106 people complete the 12 month visiting, 44 people in the CAU group, and 62 people in CM group.

\section{Demographics information}

Findings of univariate analysis comparing the experimental and control group at baseline are presented in Table 1. In general, the sociodemographic and clinical characteristics of the participants were similar between two groups.

\section{The relapse rate and withdraw rate}

There was no significant difference in relapse rate for CAU and CM group (CAU group: 5\%, CM group: $7.35 \%$ ) (Table 2); the withdraw rate was significant lower in CM group compared with CAU group of each visit (Table 3).

Table 1. Demographics at onset for the CM and CAU group.

\begin{tabular}{|c|c|c|c|}
\hline & $\begin{array}{c}\text { CAU } \\
(\mathrm{N}=60)\end{array}$ & $\begin{array}{c}\mathrm{CM} \\
(\mathrm{N}=68)\end{array}$ & Univariate statistics \\
\hline Sex & & & $\chi^{2}=0.443 ; \mathrm{ns}$ \\
\hline Male & $30(50.0 \%)$ & $30(44.1 \%)$ & \\
\hline Female & $30(50.0 \%)$ & $38(55.9 \%)$ & \\
\hline Age & $42.07(9.5)$ & $41.34(9.9)$ & $\mathrm{t}=0.423 ; \mathrm{ns}$ \\
\hline Working & & & $\chi^{2}=12.604 ; \mathrm{ns}$ \\
\hline Full time & $18(30.0 \%)$ & $9(13.2 \%)$ & \\
\hline Part time & $3(5.0 \%)$ & $1(1.5 \%)$ & \\
\hline No job & $39(65.0 \%)$ & $58(85.3 \%)$ & \\
\hline Marital status & & & $\chi^{2}=2.22 ; \mathrm{ns}$ \\
\hline Married & $15(25.0 \%)$ & $15(22.1 \%)$ & \\
\hline Single & $33(55.0 \%)$ & $40(58.8 \%)$ & \\
\hline Divorce & $12(20.0 \%)$ & $13(19.1 \%)$ & \\
\hline Disease course & $20.24(9.5)$ & $17.32(8.1)$ & $\mathrm{t}=1.87 ; \mathrm{ns}$ \\
\hline Hospitalization experience & & & $\chi^{2}=4.84 ; \mathrm{ns}$ \\
\hline Hospitalization & $42(70.0 \%)$ & $57(83.8 \%)$ & \\
\hline No hospitalization & $18(30.0 \%)$ & $11(16.2 \%)$ & \\
\hline Medication & & & $\chi^{2}=1.39 ; \mathrm{ns}$ \\
\hline Novel & $29(48.3 \%)$ & $36(52.9 \%)$ & \\
\hline Conventional & $24(40.0 \%)$ & $28(41.2 \%)$ & \\
\hline Combined & $7(11.7 \%)$ & $4(5.9 \%)$ & \\
\hline Subtype & & & $\chi^{2}=10.01 ; \mathrm{ns}$ \\
\hline Paranoid & $39(65.0 \%)$ & $52(76.5 \%)$ & \\
\hline Hebephrenic & $1(1.7 \%)$ & $3(4.4 \%)$ & \\
\hline Undifferentiated type & $4(6.7 \%)$ & 0 & \\
\hline Other & $16(26.6 \%)$ & $13(19.1 \%)$ & \\
\hline
\end{tabular}


Table 2. The relapse rate between control and experimental group.

\begin{tabular}{ccccc}
\hline & CAU & CM & Total & P value \\
\hline total & 60 & 68 & 128 & \\
relapse & 3 & 5 & 8 & \\
relapse rate & 0.05 & 0.07 & 0.06 & 0.73 \\
\hline
\end{tabular}

Table 3. The withdraw rate between control and experimental group.

\begin{tabular}{cccccccc}
\hline & \multicolumn{5}{c}{ CAU } & \multicolumn{3}{c}{ CM } & \multirow{2}{*}{ P value } \\
\cline { 2 - 6 } & Total & withdraw & Percent & Total & withdraw & Percent & \\
\hline Baseline & 60 & 0 & $0.00 \%$ & 68 & 0 & $0.00 \%$ & \\
1 month & 53 & 7 & $13.21 \%$ & 67 & 1 & $1.49 \%$ & 0.03 \\
3 month & 51 & 9 & $17.65 \%$ & 64 & 4 & $6.25 \%$ & 0.08 \\
6 month & 48 & 12 & $25.00 \%$ & 62 & 6 & $9.68 \%$ & 0.07 \\
12 month & 44 & 16 & $36.36 \%$ & 62 & 6 & $9.68 \%$ & 0.01 \\
\hline
\end{tabular}

\section{The Positive and Negative Syndrome Scale Score (PANSS)}

The primary outcomes were a change in symptoms and social function in 12 months. To assess mental symptoms, participants were measured at baseline, 1, 3,6 , and 12 months with the PANSS. As shown in the Table 4, no statistically significant differences in PANSS total score was observed between two groups of each visit to the 1 year follow-up. The change of PANSS total score of baseline to each visit was not significantly different, either (Table 5). The PANSS total score decreased significantly from baseline and each visits in both groups (Table 6). At the endpoint, the PANSS negative score of CM group was significantly improved to compare with baseline, while in CAU group, the change was not significantly.

\section{Personal and Social Performance (PSP)}

In order to assess the social function of schizophrenia patients, we used the PSP scale of baseline, 1, 3, 6, and 12 months and the results were shown in Table 4, Table 5. There was no difference between control and experimental group in each visit of PSP global score (Table 4). But the change of PSP global score of $\mathrm{CM}$ group was obvious higher than CAU group $(\mathrm{P}=0.01, \mathrm{P}=0.03)$ from 3 months to the endpoint (Table 6). Interestingly, the score was in the trend of gradually rising in both group, but only CM group had the statistical significance each visit.

\section{Social Function 36 (SF36)}

The grade in Social Function 36 (SF36) reflexes the quality of patients and we found there was no difference between CAU and CM group in each visit (Table 4) or the change of total score from baseline to each visit (Table 6). However, we can see the statistical significance when it comes to comparison of SF36 total score of baseline and each visit. 
Table 4. Comparison of different stages between control and experimental group.

\begin{tabular}{|c|c|c|c|c|}
\hline & $\begin{array}{c}\text { CAU }(\mathrm{n}=60) \\
\text { mean }(\mathrm{SD})\end{array}$ & $\begin{array}{c}\mathrm{CM}(\mathrm{n}=68) \\
\text { mean }(\mathrm{SD})\end{array}$ & $\mathrm{t}$ value & $P$ value \\
\hline \multicolumn{5}{|c|}{ PANSS total score } \\
\hline Baseline & $44.03 \pm 8.74$ & $45.50 \pm 10.81$ & 0.84 & 0.40 \\
\hline 1 month & $43.13 \pm 9.73$ & $43.04 \pm 9.38$ & 0.05 & 0.96 \\
\hline 3 month & $43.47 \pm 11.32$ & $40.95 \pm 9.15$ & 1.29 & 0.20 \\
\hline 6 month & $40.85 \pm 8.81$ & $40.85 \pm 9.16$ & 0 & 1.00 \\
\hline 12 month & $39.93 \pm 9.08$ & $39.89 \pm 9.25$ & 0.03 & 0.98 \\
\hline end point & $41.03 \pm 9.59$ & $40.93 \pm 10.69$ & 0.06 & 0.95 \\
\hline \multicolumn{5}{|c|}{ PSP total score } \\
\hline Baseline & $71.25 \pm 17.70$ & $67.76 \pm 12.91$ & 2.00 & 0.05 \\
\hline 1 month & $70.96 \pm 17.74$ & $73.09 \pm 12.32$ & 0.66 & 0.51 \\
\hline 3 month & $72.60 \pm 15.39$ & $74.21 \pm 11.08$ & 0.64 & 0.53 \\
\hline 6 month & $74.81 \pm 11.47$ & $74.65 \pm 11.21$ & 0.08 & 0.94 \\
\hline 12 month & $76.55 \pm 11.10$ & $76.44 \pm 10.42$ & 0.05 & 0.96 \\
\hline end point & $75.35 \pm 10.90$ & $75.54 \pm 11.68$ & 0.10 & 0.92 \\
\hline \multicolumn{5}{|c|}{ SF36 total score } \\
\hline Baseline & $103.69 \pm 13.27$ & $99.50 \pm 14.62$ & 1.68 & 0.10 \\
\hline 1 month & $104.74 \pm 12.47$ & $103.72 \pm 13.40$ & 0.43 & 0.67 \\
\hline 3 month & $105.73 \pm 13.51$ & $103.81 \pm 12.77$ & 0.78 & 0.44 \\
\hline 6 month & $104.15 \pm 15.95$ & $102.65 \pm 12.54$ & 0.55 & 0.58 \\
\hline 12 month & $104.91 \pm 13.90$ & $103.85 \pm 12.68$ & 0.41 & 0.69 \\
\hline end point & $102.47 \pm 20.24$ & $102.57 \pm 13.95$ & 0.04 & 0.97 \\
\hline \multicolumn{5}{|c|}{ SSMI total score } \\
\hline Baseline & $35.85 \pm 16.13$ & $39.96 \pm 15.43$ & 1.47 & 0.15 \\
\hline 1 month & $36.23 \pm 15.67$ & $36.84 \pm 14.34$ & 0.22 & 0.83 \\
\hline 3 month & $36.57 \pm 15.46$ & $38.09 \pm 16.81$ & 0.50 & 0.62 \\
\hline 6 month & $35.96 \pm 17.16$ & $40.50 \pm 16.15$ & 1.42 & 0.16 \\
\hline 12 month & $37.43 \pm 17.44$ & $38.66 \pm 15.59$ & 0.38 & 0.70 \\
\hline end point & $38.02 \pm 18.07$ & $39.63 \pm 15.57$ & 0.54 & 0.59 \\
\hline \multicolumn{5}{|c|}{ RSESE total score } \\
\hline Baseline & $0.91 \pm 0.99$ & $1.07 \pm 1.27$ & 0.77 & 0.44 \\
\hline 1 month & $0.79 \pm 1.03$ & $0.85 \pm 1.32$ & 0.27 & 0.79 \\
\hline 3 month & $1.12 \pm 1.63$ & $0.78 \pm 1.35$ & 1.20 & 0.23 \\
\hline 6 month & $0.73 \pm 0.89$ & $0.79 \pm 1.22$ & 0.29 & 0.77 \\
\hline 12 month & $0.68 \pm 0.91$ & $0.94 \pm 1.90$ & 0.82 & 0.41 \\
\hline end point & $0.66 \pm 0.88$ & $1.00 \pm 1.89$ & 1.27 & 0.21 \\
\hline
\end{tabular}


Table 5. Comparison of PANSS score change between control and experimental group.

\begin{tabular}{|c|c|c|c|c|c|c|c|c|}
\hline & \multicolumn{4}{|c|}{$\begin{array}{c}\text { CAU }(\mathrm{n}=60) \\
\text { mean }(\mathrm{SD})\end{array}$} & \multicolumn{4}{|c|}{$\begin{array}{c}\mathrm{CM}(\mathrm{n}=68) \\
\text { mean }(\mathrm{SD})\end{array}$} \\
\hline & $\begin{array}{c}\text { PANSS } \\
\text { total } \\
\text { score }\end{array}$ & $\begin{array}{c}\text { PANSS } \\
\text { positive } \\
\text { score }\end{array}$ & $\begin{array}{c}\text { PANSS } \\
\text { negative } \\
\text { score }\end{array}$ & $\begin{array}{c}\text { PANSS } \\
\text { general } \\
\text { score }\end{array}$ & $\begin{array}{c}\text { PANSS } \\
\text { total } \\
\text { score }\end{array}$ & $\begin{array}{l}\text { PANSS } \\
\text { positive } \\
\text { score }\end{array}$ & $\begin{array}{c}\text { PANSS } \\
\text { negative } \\
\text { score }\end{array}$ & $\begin{array}{c}\text { PANSS } \\
\text { general } \\
\text { score }\end{array}$ \\
\hline Baseline & $44.03 \pm 8.74$ & $9.68 \pm 2.68$ & $11.52 \pm 4.50$ & $22.82 \pm 4.95$ & $45.50 \pm 10.81$ & $10.38 \pm 4.19$ & $11.91 \pm 4.22$ & $23.10 \pm 5.18$ \\
\hline 1 month & $43.13 \pm 9.73$ & $10.66 \pm 11.34$ & $11.79 \pm 4.63$ & $22.00 \pm 5.43$ & $43.04 \pm 9.38$ & $9.85 \pm 3.27$ & $11.46 \pm 4.50$ & $21.84 \pm 4.79$ \\
\hline 3 month & $43.47 \pm 11.32$ & $9.02 \pm 2.84$ & $11.98 \pm 4.60$ & $22.22 \pm 6.20$ & $41.20 \pm 9.30^{*}$ & $9.17 \pm 3.26^{*}$ & $11.45 \pm 4.31$ & $20.69 \pm 4.22^{* *}$ \\
\hline 6 month & $40.85 \pm 8.81$ & $8.58 \pm 2.15$ & $12.83 \pm 9.45$ & $20.98 \pm 4.77$ & $40.85 \pm 9.16^{* *}$ & $8.97 \pm 2.72^{*}$ & $11.00 \pm 3.77$ & $20.71 \pm 4.53^{* *}$ \\
\hline 12 month & $39.93 \pm 9.08^{*}$ & $8.39 \pm 1.91$ & $10.86 \pm 4.22$ & $20.43 \pm 4.67^{*}$ & $39.89 \pm 9.25^{* *}$ & $8.84 \pm 2.59^{* *}$ & $10.45 \pm 4.10^{*}$ & $20.44 \pm 4.41^{* *}$ \\
\hline
\end{tabular}

${ }^{\star}, \mathrm{P}<0.05$ compare with baseline; ${ }^{* *}, \mathrm{P}<0.01$ compare with baseline.

Table 6. Changes of PANSS, PSP and SF36 score from different stage to baseline.

\begin{tabular}{|c|c|c|c|c|c|c|}
\hline & \multicolumn{3}{|c|}{$\mathrm{CAU}(\mathrm{n}=60)$} & \multicolumn{3}{|c|}{$\mathrm{CM}(\mathrm{n}=68)$} \\
\hline & PANSS & PSP & SF36 & PANSS & PSP & SF36 \\
\hline 1 month - Baseline & $-1.05 \pm 5.45$ & $-0.72 \pm 13.00$ & $0.22 \pm 9.05$ & $-1.84 \pm 6.56$ & $4.24 \pm 8.04^{*}$ & $3.56 \pm 8.34^{*}$ \\
\hline 3 month - Baseline & $-0.48 \pm 7.94$ & $-1.12 \pm 16.18$ & $0.95 \pm 0.68$ & $-3.66 \pm 7.04$ & $4.99 \pm 8.26^{*}$ & $3.50 \pm 9.81$ \\
\hline 12 month - Baseline & $-3.00 \pm 7.72$ & $3.3 \pm 10.59$ & $0.5 \pm 10.19$ & $-4.57 \pm 8.15$ & $7.78 \pm 11.30^{*}$ & $3.07 \pm 10.33$ \\
\hline end point - Baseline & $-3.00 \pm 7.72$ & $3.3 \pm 10.59$ & $0.5 \pm 10.19$ & $-4.57 \pm 8.15$ & $7.78 \pm 11.30^{*}$ & $3.07 \pm 10.33$ \\
\hline
\end{tabular}

${ }^{\star}, \mathrm{P}<0.05$ compare with CAU group; ${ }^{\star *}, \mathrm{P}<0.01$ compare with CAU group.

\section{Stigma Scale Mental Illness (SSMI)}

Like the result of SF36, there was no difference between CAU and CM group in each visit of stigma scale mental illness (SSMI) grade (Table 4) while when it comes to comparison of SSMI total score of baseline and each visits, we can see the statistical significance of experimental group of visit 3.

\section{A Rating Scale for Extrapyramidal Side Effects (RSESE)}

There was no difference between CAU and CM group in each visit of RSESE total score (Table 4) or comparison of RSESE total score between baseline and each visit.

\section{Other outcomes}

For patients with schizophrenia, there are some other outcomes to evaluate the changes in their overall situation including the frequency of communication with doctors, the compliance with medication, the treatment effect evaluation and self-satisfaction. We can see the higher frequency of communication with doctors in visit $1(\mathrm{p}<0.01)$ and visit $2(\mathrm{p}=0.02)$ and become similar in other visit to the progress of treatment (Table 7). 
Table 7. The frequency of communication with doctors.

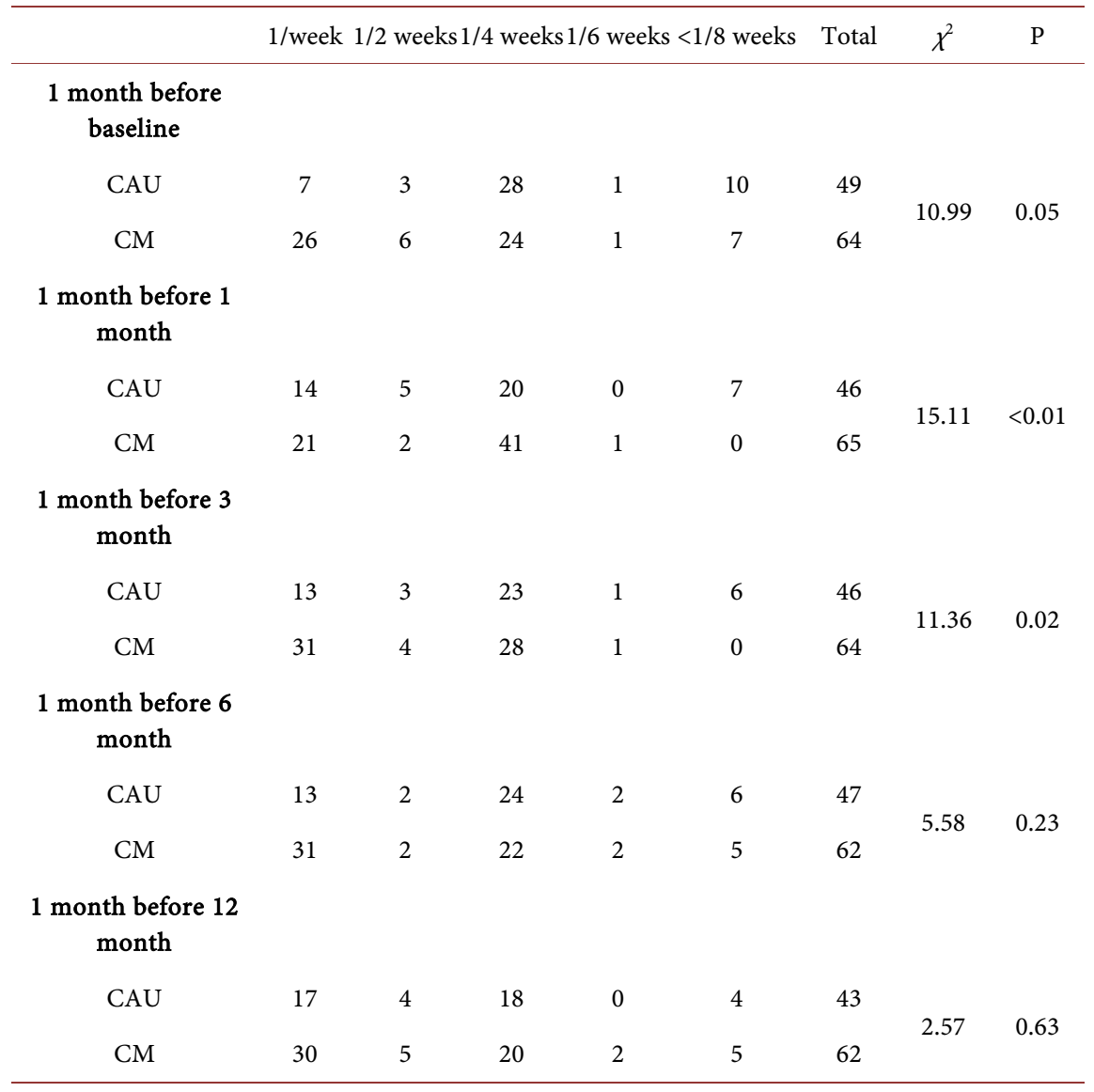

\section{Discussion}

In this study, we examined the effectiveness of a CM group compared to a CAU group of 128 patients with schizophrenia from outpatient clinic of community of Haidian District in china. The demographic information shows no different between CM and CAU group. Which means the sociodemographic and clinical characteristics of the participants were similar between two groups.

In the end of this study, which shows there was no significant difference in relapse rate for two groups (CAU group: 5\%, CM group: 7\%). However, this relapse rate was much lower than we estimated the sample size. Part of the reason is because the clients are chronic patients (disease course CAU group 20 year, $\mathrm{CM}$ group 17 year), and they are all in the community mental health management system. The sample size maybe not sufficient to identify the difference between the two groups. As suggested by some authors, [18] certain outcomes of $\mathrm{CM}$ practices for persons with CAU do not appear in a short-term perspective (i.e. between 6 and 24 months).

The withdraw rate was significant lower in CM group compared with CAU group, which means the CM group patients have a better compliance, which is very important to the treatment of schizophrenia patients. The result is same to the study which indicated that people receiving case management was more 
likely to remain in contact with services than those receiving usual care [19]. Although based on not high quality evidence, compared to usual care, another study also said that ICM (one of the case management model) may increase retention in care [3].

PANSS were assessed at baseline, 1, 3, 6, and 12 months. Our results show there is no statistically significant differences in PANSS total score of two groups of each visit to the 1 year follow-up. But we could see some difference when identify the change in baseline and each visits. At the endpoint, the PANSS negative score of CM group was significantly improved to compare with baseline, while in CAU group, the change was not significantly. Negative symptom is a big challenge to schizophrenia treatment, suggest maybe CM is an efficacy treatment to improve negative symptoms, [20] which requires further exploration. EYH Chen found that the case management group had better function, fewer negative symptoms, general psychopathology, and depressive symptoms [21]. The Occupational Functioning Assessment Scale (SOFAS) and Role Functioning Scale scores in the case management group improved significantly from baseline to 6 months, and from 6 to 12 months patients in the case management group attained significant functional improvement. The negative symptom score also evident changed from baseline to endpoint. But, in this study, both groups of patients are with early psychosis and have received 2 years of early intervention before starting the research. But at the same time, it is also suggested that perhaps with the extension of intervention time, we may get better results.

There was no difference between control and experimental group in each visit of PSP global score. But, at the endpoint, the PSP score of CM group was significantly higher compared with baseline, while CAU group was not significantly changed. This indicates the functionality of CM group was significantly improved, while CAU group was not. In this study, we evaluate patients' function of four domains socially useful activities, personal and social relationships, self-care, and disturbing and aggressive behavior. This improvement on the functionality of CM group is consistent with previous findings. Its results show an overall positive impact on the CM service on participants' self-report outcomes of several domains that CM participants improved in self-efficacy, unmet needs, and general quality of life, and set more goals than the control group [22]. A before review also had showed case management globally improved social functioning, although it social's effect on mental state and quality of life remains unclear [3]. But, a recent research suggested that functional outcomes improved significantly on the two forms of community-based psychosocial treatments in contrast to the treatment as usual group, which contains case management [23].

Lin $\mathrm{CH}$ suggested that clinical symptoms, mainly negative symptoms, mediate the influence of neurocognition and social cognition on functional outcome of schizophrenia [24]. Our study also showed both improves in the negative symptoms and in PSP scores which representing social function that was consistent with their correlation, although we did not have statistical data on neurological and social cognition in this study. We can improve this aspect in the future. 
This study has several limitations. Firstly, the one year follow-up maybe is short for the more outcomes happening. Secondly, the sample size was relatively small and could only represent the small group with schizophrenia. Thirdly, in this study we did not statistic the rate of patients using long-acting antipsychotics and lack of pharmacokinetic data to monitor adherence.

\section{Conclusion}

This study assessed the effectiveness of case management on schizophrenia patients by using different scales. The relapse rate was similar in 2 groups, while the compliance rate was significantly better in CM group. And there is a possible effectiveness of CM group of improving negative symptoms and social function in schizophrenia clients.

\section{Disclosure}

The authors declared no conflicts of interest.

\section{Acknowledgements}

The authors would like to thank Li-Li Zhang from Xian Janssen medical department for giving valuable suggestion when develop the manuscript and thank Prof. Carol Harvey from Psychosocial Research Centre (Department of Psychiatry), The University of Melbourne, Melbourne, Australia for the valuable suggestion when develop the study and the manuscript.

\section{Funding}

This study was supported by the Clinical Characteristics of the Capital of Beijing science and Technology commission Foundation of China (D101100050010071) and Capital Health Development Research Project Program of China (2014-4-4112).

\section{Conflicts of Interest}

The authors declare no conflicts of interest regarding the publication of this paper.

\section{References}

[1] Caceda, R., Nemeroff, C.B. and Harvey, P.D. (2014) Toward an Understanding of Decision Making in Severe Mental Illness. The Journal of Neuropsychiatry and Clinical Neurosciences, 26, 196-213.

https://doi.org/10.1176/appi.neuropsych.12110268

[2] Taborda Zapata, E.M., Montoya Gonzalez, L.E., Gomez Sierra, N.M., Arteaga Morales, L.M. and Correa Rico, O.A. (2016) Intervention of Schizophrenia from the Community Model. The Revista Colombiana de Psiquiatría, 45, 46-50. https://doi.org/10.1016/j.rcp.2015.09.001

[3] Dieterich, M., Irving, C.B., Bergman, H., Khokhar, M.A., Park, B. and Marshall, M. (2017) Intensive Case Management for Severe Mental Illness. Schizophrenia Bulletin, 43, 698-700. https://doi.org/10.1093/schbul/sbx061 
[4] Mueser, K.T., Bond, G.R., Drake, R.E. and Resnick, S.G. (1998) Models of Community Care for Severe Mental Illness: A Review of Research on Case Management. Schizophrenia Bulletin, 24, 37-74. https://doi.org/10.1093/oxfordjournals.schbul.a033314

[5] Solomon, P. (1992) The Efficacy of Case Management Services for Severely Mentally Disabled Clients. Community Mental Health Journal, 28, 163-180. https://doi.org/10.1007/BF00756815

[6] Gray, A.M., Marshall, M., Lockwood, A. and Morris, J. (1997) Problems in Conducting Economic Evaluations alongside Clinical Trials. Lessons from a Study of Case Management for People with Mental Disorders. The British Journal of Psychiatry, 170, 47-52. https://doi.org/10.1192/bjp.170.1.47

[7] Holloway, F., Oliver, N., Collins, E. and Carson, J. (1995) Case Management: A Critical Review of the Outcome Literature. European Psychiatry, 10, 113-128. https://doi.org/10.1016/0767-399X(96)80101-5

[8] Kim, S.W., Lee, G.Y., Yu, H.Y., Jung, E.I., Lee, J.Y., Kim, S.Y., et al. (2017) Development and Feasibility of Smartphone Application for Cognitive-Behavioural Case Management of Individuals with Early Psychosis. Early Intervention in Psychiatry, 12, 1087-1093. https://doi.org/10.1111/eip.12418

[9] Marshall, M., Lockwood, A. and Gath, D. (1995) Social Services Case-Management for Long-Term Mental Disorders: A Randomised Controlled Trial. The Lancet, 345, 409-412. https://doi.org/10.1016/S0140-6736(95)90399-2

[10] Mohamed, S. (2017) Evaluating the Quality of Rural Intensive Case Management Services Using Administrative Data: An Exploratory Study. Psychiatric Quarterly, 88, 897-907. https://doi.org/10.1007/s11126-017-9505-Z

[11] Bjorkman, T., Hansson, L. and Sandlund, M. (2002) Outcome of Case Management Based on the Strengths Model Compared to Standard Care. A Randomised Controlled Trial. Social Psychiatry and Psychiatric Epidemiology, 37, 147-152. https://doi.org/10.1007/s001270200008

[12] Rapp, C.A. and Goscha, R.J. (2006) The Strengths Model: Case Management with People with Psychiatric Disabilities. 2nd Edition, Oxford University Press, Oxford.

[13] Cheng, J.J., Ho, H., Chang, C.J., Lan, S.Y. and Hwu, H.G. (1996) Positive and Negative Syndrome Scale (PANSS): Establishment and Reliability Study of a Mandarin Chinese Language Version. Chinese Journal of Psychiatry, 10, 251-258.

[14] Morosini, P.L., Magliano, L., Brambilla, L., Ugolini, S. and Pioli, R. (2000) Development, Reliability and Acceptability of a New Version of the DSM-IV Social and Occupational Functioning Assessment Scale (SOFAS) to Assess Routine Social Functioning. Acta Psychiatrica Scandinavica, 101, 323-329. https://doi.org/10.1111/j.1600-0447.2000.tb10933.x

[15] Li, L., Wang, H. and Shen, Y. (2002) Development and Psychometric Tests of a Chinese Version of the SF-36 Health Survey Scales. Chinese Journal of Preventive Medicine, 36, 109-113.

[16] Zeng, Q.Z., He, Y.L., Tian, H., Miao, J.M. and Yu, W.K. (2009) The Preliminary Preparation of Stigma Evaluation Scale for Mental Patients. Chinese Mental Health Journal, 21, 634-637.

[17] Simpson, G.M. and Angus, J.W. (1970) A Rating Scale for Extra Pyramidal Side Effects. Acta Psychiatrica Scandinavica, 212, 11-19. https://doi.org/10.1111/j.1600-0447.1970.tb02066.x

[18] Burns, T., Catty, J., Dash, M., Roberts, C., Lockwood, A. and Marshall, M. (2007) Use of Intensive Case Management to Reduce Time in Hospital in People with Se- 
vere Mental Illness: Systematic Review and Meta-Regression. BMJ, 335, 336. https://doi.org/10.1136/bmj.39251.599259.55

[19] Marshall, M., Gray, A., Lockwood, A. and Green, R. (2011) WITHDRAWN: Case Management for People with Severe Mental Disorders. Cochrane Database of Systematic Reviews, No. 4, CD000050. https://doi.org/10.1002/14651858.CD000050.pub2

[20] Best, M.W., Grossman, M., Oyewumi, L.K. and Bowie, C.R. (2016) Examination of the Positive and Negative Syndrome Scale Factor Structure and Longitudinal Relationships with Functioning in Early Psychosis. Early Intervention in Psychiatry, 10, 165-170. https://doi.org/10.1111/eip.12190

[21] Chen, E.Y., Chang, W.C., Chan, S.K., Lam, M.M., Hung, S.F., Chung, D.W., et al. (2015) Three-Year Community Case Management for Early Psychosis: A Randomised Controlled Study. Hong Kong Medical Journal, 21, 23-26.

[22] Gelkopf, M., Lapid, L., Werbeloff, N., Levine, S.Z., Telem, A., Zisman-Ilani, Y., et al. (2016) A Strengths-Based Case Management Service for People with Serious Mental Illness in Israel: A Randomized Controlled Trial. Psychiatry Research, 241, 182-189. https://doi.org/10.1016/j.psychres.2016.04.106

[23] Varga, E., Endre, S., Bugya, T., Tenyi, T. and Herold, R. (2018) Community-Based Psychosocial Treatment Has an Impact on Social Processing and Functional Outcome in Schizophrenia. Frontiers in Psychiatry, 9, 247.

https://doi.org/10.3389/fpsyt.2018.00247

[24] Lin, C.H., Huang, C.L., Chang, Y.C., Chen, P.W., Lin, C.Y., Tsai, G.E., et al. (2013) Clinical Symptoms, Mainly Negative Symptoms, Mediate the Influence of Neurocognition and Social Cognition on Functional Outcome of Schizophrenia. Schizophrenia Research, 146, 231-237. https://doi.org/10.1016/j.schres.2013.02.009

\section{List of Abbreviations}

CM: Case management;

CAU: Care as usual;

PANSS: Positive and Negative Syndrome Scale;

PSP: Personal and Social Performance Scale;

SSMI: Stigma scale mental illness;

ACT model: Assertive Community Treatment model;

ICD-10: International Classification of Diseases-10;

SF36: The Social Function 36 Scale;

RSESE: Rating Scale for Extrapyramidal Side Effects;

LOCF: Last Observation Carried Forward;

SPSS: Statistical Product and Service Solutions;

SOFAS: Occupational Functioning Assessment Scale (SOFAS). 